\title{
Wide-band Rock and Ore Samples Complex Permittivity Measurement
}

\author{
Sixin Liu ${ }^{1}$, Junjun $\mathrm{Wu}^{1}$, Lili Zhang ${ }^{2}$ and Hang Dong ${ }^{3}$ \\ ${ }^{1}$ Jilin University, \\ 2Shenyang Aerospace University, \\ ${ }^{3}$ Northeast Institute of Geography and Agroecology, CAS
}

China

\section{Introduction}

Ground penetrating radar (GPR) is based on high-frequency electromagnetic wave propagation and its detecting targets are below the ground surface (Daniels, 2004; Jol, 2009). Velocity and attenuation are two important factors describing the electromagnetic wave in the media composed of rocks or soils. Velocity is inverse proportional to the root of the permittivity while other parameters are fixed generally. In order to understand the performance of GPR, permittivity testing and analysis are critical. In addition, during the metal ore exploration by borehole radar which is an operating mode of GPR, the permittivity difference between ore body and surrounding rock is the foundation for exploration. As the sampling site, geological environment, and seasons are changing, the permittivity are different even for the same rock. Therefore, permittivity measurement is very important.

Currently, measurement methods are basically indirect methods which are based on transmission line theory, characteristic impedance, and propagation constant. These variables have intrinsic relationship with permittivity which can be inverted from the measured data by certain calculation procedure. At the RF frequency band, common measurement methods include short-circuited wave-guide measurement, coaxial line transmission/reflection method, open-ended coaxial probe, resonant cavity method, freespace transmission technique, parallel-plate capacitance method, etc.

Roberts and von Hippel (1946) developed the short-circuited wave-guide measurement, sample is inserted at the end of the wave-guide or coaxial line, the standing wave is formed as the incident wave and the reflected wave coexist in the wave-guide. The sanding wave ratios (SWR's) were required to measure in the case with and without sample. Permittivity can be determined by the change in the widths of nodes, sample length, and the waveguide dimension.

Resonant cavity method is a perturbation technique, which is frequently used for measuring permittivity because of its simplicity, accuracy, and high temperature capability (Venkatesh \& Raghavan, 2005). This technique is based on the resonant frequency shift, and the change in absorption characteristics due to the insertion of sample material. The measurement is made by placing a sample completely in the center of a waveguide. The size of the cavity is 
designed for special frequency. Calibration is required before measurement, once the calibration is finished, the measurement is fast. The samples preparation is little difficult.

Free-space transmission technique is carried out by placing the sample between the transmitting and the receiving antennas (Kraszewski, 1980). The electrical parameters can be calculated by measuring the attenuation and the phase shift in the media. Free-space measurement can measure permittivity in a wide frequency band. It is a no-destructive and contact-less method. The frequency can be as high as $30 \mathrm{GHz}$. The usual assumption for this technique is that a uniform plane wave incident upon the flat surface of a homogeneous material, and the planar sample has infinite extent laterally (Venkatesh \& Raghavan, 2005).

Parallel disk capacitor technique (Shi \& Shen, 1989; Shen, Marouni, Zhang, \& shi, 1987) is based on the theory that the capacitance is dependant on the medium permittivity filling the capacitor. As a capacitor is filled with medium having permittivity of $\varepsilon_{r}$, its capacitance $C$ is $\varepsilon_{r}$ times of vacuum capacitance $C_{0}$. If we measure the capacitance before and after the capacitor is filled with the medium, we can obtain the permittivity. This method is mainly fitted for low-frequency range between $20 \mathrm{MHz}-200 \mathrm{MHz}$.

Coaxial reflection/transmission method was introduced by Nicolson, Rose, and Wire, in 1970s, therefore, it is also called NRW method (Nicolson \&Ross, 1970; Weir, 1974). The material under test (MUT) is inserted into coaxial line (waveguide). As the electromagnetic wave is traveling in the line, it meets the MUT, a part of the wave is transmitted, and the other is reflected. Attenuation and phase shift occur at the same time. Vector network analyzer (VNA) can measure the reflection and transmission coefficients at a wide frequency range. The permittivity can be inverted by electromagnetic theory from these measured data. This technique was first used for rock measurement (Shen, 1985), and the waterbearing, oil-bearing, or gas-bearing rocks can be distinguished from the measured data. Coutanceau-Monteil and Jacquin improved this technique in 1993. The rock samples are coated with a low melting point alloy and this improvement enables measurements to be made on larger samples and avoids air-gap correction at the solid-cell interface. However, the sample preparation is still difficult.

Open-ended coaxial probe technique (Zhen \&Smith, 1991; Blackham\&Pollard, 1997; Hoshina, Kanai, Miyakawa, 2001) is a technique of which the open-end of a coaxial is touched on the MUT, and the other end is connected to a VNA. The measured reflection coefficient is used to invert the permittivity. A flange is connected to the open-end to improve the accuracy. The circular waveguide probe, the rectangular waveguide probe, and the coaxial probe are often used. The coaxial probe can be used at frequency-domain, timedomain, point frequency, and it is suitable for kinds of media with different electric characteristic (low to high permittivity, lossy or lossless, magnetic lossy materials). This method is no-destructive, no-intrusive, and also characterized with wide frequency band, simple and open structure. It is fitted for on-line, in-vivo, and in-situ testing, it is receiving the attention from many scientists and engineers.

Open-ended probe electromagnetic radiation dates back to 1950s or earlier. Open-ended measurement technique was improved rapidly in recent 20 years (Stuchly M.A. \& Stutch, S.S, 1980). It was first introduced and applied for biological tissue measurement at RF frequency, and was used for dielectric material testing at RF band shortly, and the lumped parameter model is used at the time for data processing. Later, as the testing frequency expanded to $\mathrm{X}$ and $\mathrm{Ku}$ band, quisi-static analysis model (Misra, 1987; Fans et al., 1952; Nyshadham et al., 1992; Wei, \& Sridhar, 1991; Blackham \& Pollard, 1997; Nelson\& Bartley, 
1998) and full-wave analysis model (Li \& Chen, 1995) appeared, and the testing material also expanded to high permittivity from low permittivity. But the sample thickness was infinite. Until the early stage of 1990s, spectral-domain quisi-static analysis model appeared, and it was suitable for multi-layered material with finite thickness. Then, many researchers analyzed the high modes in the coaxial line, and reached the spectral-domain full-wave analysis model which is a complete mathematic model.

Several rules must be considered before we choose the techniques for measurement, such as frequency range preferred, sample preparation easiness, the equipments accessible. We choose open-ended coaxial probe technique backed by metal plate because the model is easy to be analyzed, the samples making is relatively easy, and the VNA is accessible for us.

We used open-ended coaxial probe to measure 342 samples within 31 categories from 6 mine sites, including: (1) granite, marble, hybrid diorite, altered hornblende pyroxenite, pyroxene peridotite, low-grade ore, medium-grade ore, high-grade ore from the Changren nickel-cupper mine, Jilin province, China; (2) tuffaceous fine-grained sandstone, tuffaceous breccia, dacitoid crystal tuff, dacite, crystal tuff, low-grade ore, medium-grade ore, highgrade ore, and pyrite from the Huanghuagou lead-zinc mine, Chifeng, Inner Mongolian, China; (3) altered K-feldspar granite, high-grade ore, low-grade ore from the Nianzigou Molybdenum mine, Chifeng, Inner Mongolian, China; (4) albite rhyolite porphyry, breccia porphyry, quartz albitophyre, albitophyre copper, malachite copper oxide ore from the Qunji copper mine, Xinjiang, China; (5) vesicular amygdaloidal andesite, massive diorite, andesitic copper ore from the Musi copper mine, Xinjiang, China; (6) glutenite, copper ore, lead-zinc ore from the Zengnan copper mine, Xinjiang, China. It is found that high-grade ore can be distinguished from surrounding rocks by permittivity, low-grade ore shows similar permittivity as other veins. We first measured and analyzed so many samples including different rocks and ores at wide frequency range according to current references world widely.

\section{Open-ended coaxial technique}

Firstly, the theory of open-coaxial probe technique is introduced. Then, the single-layered short-circuit spectral domain quasi-static model is established. Finally, the permittivity is calculated through the optimized inversion procedure.

\subsection{The open-coaxial probe technique}

The process of open-ended coaxial probe measuring medium includes three steps.

The first step is experimental testing (hardware operation). Reflection coefficient, which contains electromagnetic parameters information of the material, is measured by an opencoaxial probe with a flange-plane connected to reflection equipment which may be vector reflectometry (vector network analyzer or six ports) or scalar reflectometry. The vector network analyzer is used here (Agilent E5071B). The second step is the theoretical modeling. The physics model for the measurement is built based on electromagnetic knowledge. Namely, the relationship between the reflection coefficient of open-coaxial probe and the electromagnetic parameters of the sample measured is usually complicated and nonlinear one. And this modeling process is also called forward process. The third step is about the rebuilding electromagnetic parameters. In this step, the electromagnetic parameters corresponding with reflection coefficient of the material measured are obtained. This 
process is often called inverse process. Because the equations established are often nonlinear, we often use numerical solution.

Both theoretical modeling and numerical inversion are important steps in electromagnetic parameters measurement technology. Their accuracy decides the reliability of the measured results. For open-coaxial probe technique, modeling process is a mathematics analysis process, while the inversion is a process of appropriate optimization iteration.

\subsection{Spectral-domain quasi-static reflection coefficient model}

At present, popular analysis models used are full wave model and quasi-static model. The former is a theory model solved according to electromagnetic field. But the latter ignores the influences of high-order mode to reflection coefficient near the aperture of a coaxial probe. In theory, full wave model can accurately measure dielectric properties of materials. In fact, some theories and test indicate that the model error introduced by ignoring high-order mode is equal to the measuring error induced by the hardware and the operation. So, we can use quasi-static model (Wu et al., 2000), if the measurement error cannot be ignored and the rapid data processing is wanted.

We use spectral-domain quasi-static method here. The flow chart for the measurement is as shown in Fig. 1. Firstly, the reflection coefficient of a MUT is measured by a VNA. Then the measured reflection coefficient is calibrated (or corrected) to achieve real reflection coefficient. Finally the permittivity is calculated through inversion from the reflection coefficient.

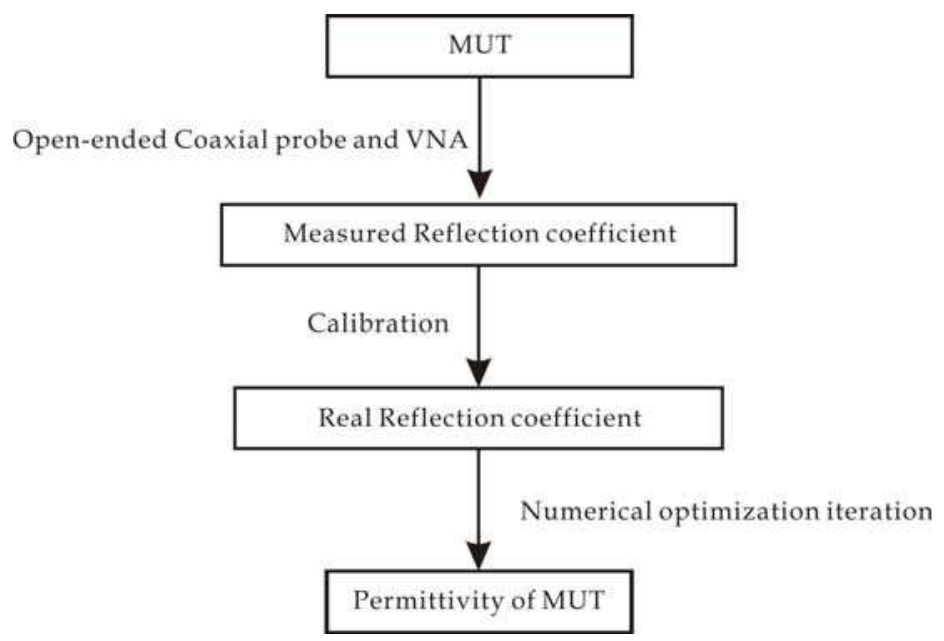

Fig. 1. Measurement flow chart

We used a single-layered short-circuit model here. Fig. 2 shows a schematic diagram of open-ended coaxial probe. " $a$ " is the radius of inner conductor of coaxial probe. " $b$ " is the radius of outer conductor. " $\mathrm{d}$ " is the thickness of sample measured. " $\varepsilon_{1}$ " and " $\mu_{1}$ " are relative permittivity and relative magnetic conductivity of the medium filled in coaxial probe. " $\varepsilon_{\mathrm{s}}$ " and " $\mu_{\mathrm{s}}$ " are permittivity and relative magnetic conductivity of the sample measured. 


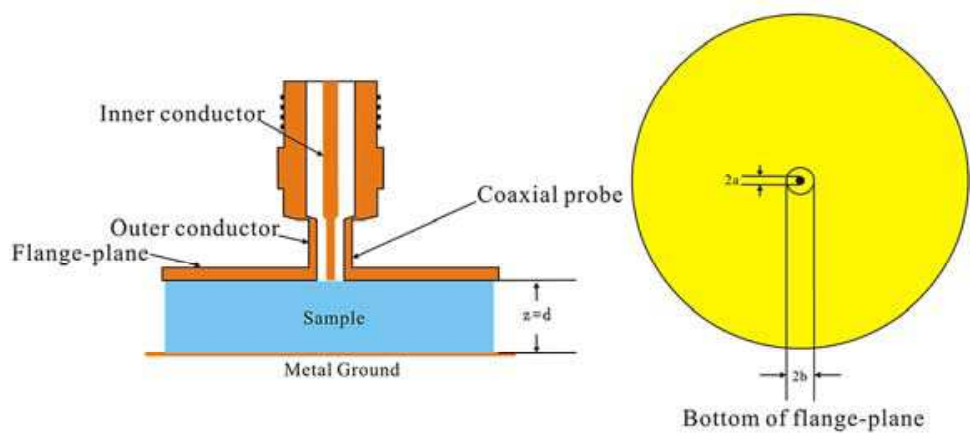

Fig. 2. Open-ended coaxial probe schematic diagram

It is assumed that only the TEM mode wave is traveling in coaxial probe and the timeharmonic factor $\mathrm{e}^{\mathrm{j} \omega \mathrm{t}}$ is ignored. The complex electric field and complex magnetic field of forward wave and backward wave in coaxial probe can be expressed respectively as,

$$
\begin{aligned}
E_{r 1} & =\frac{A}{r}\left[\exp \left(-j k_{1} z\right)+\Gamma \exp \left(j k_{1} z\right)\right] \\
H_{\varphi 1} & =\frac{A}{\eta_{1} r}\left[\exp \left(-j k_{1} z\right)-\Gamma \exp \left(j k_{1} z\right)\right]
\end{aligned}
$$

where, $\mathrm{r}, \varphi$ and $\mathrm{z}$ are the coordinate variable of cylindrical coordinate system in the equations. $\mathrm{k}_{1}=\omega \sqrt{\mu_{0} \varepsilon_{0} \mu_{1} \varepsilon_{1}}, \eta_{1}=\sqrt{\mu_{0} \mu_{1} /\left(\varepsilon_{0} \varepsilon_{1}\right)} \cdot \varepsilon_{0}, \quad \mu_{0}$ are the permittivity and magnetic conductivity in the vacuum. $\omega$ is the angular frequency.$\Gamma$ is the reflection coefficient. A is the electric field amplitude of the forward wave on probe terminal surface.

The electromagnetic field $\mathrm{E}_{\mathrm{rs}}, \mathrm{H}_{\varphi \mathrm{s}}$ in the material measured can be expressed as the integral sum of all plane waves (including high-order mode) in spectral domain.

$$
\begin{gathered}
E_{r s}=\int_{0}^{\infty} \mathrm{B}\left(\mathrm{k}_{\mathrm{c}}\right)\left[\exp (-\gamma \mathrm{z})+\Gamma_{\mathrm{b}}\left(\mathrm{k}_{\mathrm{c}}\right) \exp (\gamma \mathrm{z})\right] \mathrm{J}_{1}\left(\mathrm{k}_{\mathrm{c}} \mathrm{r}\right) \mathrm{k}_{\mathrm{c}} \mathrm{dk}_{\mathrm{c}} \\
\mathrm{H}_{\varphi \mathrm{s}}=\int_{0}^{\infty} \mathrm{B}\left(\mathrm{k}_{\mathrm{c}}\right) \mathrm{Y}\left(\mathrm{k}_{\mathrm{c}}\right)\left[\exp (-\gamma \mathrm{z})-\Gamma_{\mathrm{b}}\left(\mathrm{k}_{\mathrm{c}}\right) \exp (\gamma \mathrm{z})\right] \mathrm{J}_{1}\left(\mathrm{k}_{\mathrm{c}} \mathrm{r}\right) \mathrm{k}_{\mathrm{c}} \mathrm{dk_{ \textrm {c } }}
\end{gathered}
$$

In the equations, $\gamma=\sqrt{\mathrm{k}_{\mathrm{c}}^{2}-\mathrm{k}_{\mathrm{s}}^{2}}$, and $\operatorname{Re}(\gamma) \geq 0, \mathrm{k}_{\mathrm{s}}=\omega \cdot \sqrt{\mu_{0} \varepsilon_{0} \mu_{\mathrm{s}} \varepsilon_{\mathrm{s}}}, \mathrm{Y}\left(\mathrm{k}_{\mathrm{c}}\right)=j \omega \varepsilon_{0} \varepsilon_{\mathrm{s}} / \gamma$, $\Gamma_{b}\left(k_{c}\right)=-\exp (-2 \gamma d), \quad J_{1}(x)$ is first-order first-kind Bessel function, $B\left(k_{c}\right)$ is the field amplitude expressed in the spectral domain. $\mathrm{k}_{\mathrm{c}}$ is the continuous eigenvalue.

As the boundary conditions at the $\mathrm{z}=0$ plane are satisfied, the tangent components of the field are equal; following equations can be derived,

$$
\begin{aligned}
& \int_{0}^{\infty} \mathrm{B}\left(\mathrm{k}_{\mathrm{c}}\right)\left[1+\Gamma_{\mathrm{b}}\left(\mathrm{k}_{\mathrm{c}}\right)\right] \mathrm{J}_{1}\left(\mathrm{k}_{\mathrm{c}} \mathrm{r}\right) \mathrm{k}_{\mathrm{c}} \mathrm{dk} \mathrm{k}_{\mathrm{c}}= \begin{cases}\frac{\mathrm{A}(1+\Gamma)}{\mathrm{r}} & \mathrm{a} \leq \mathrm{r} \leq \mathrm{b} \\
0 & \mathrm{r} \leq \mathrm{a}, \mathrm{r} \geq \mathrm{b}\end{cases} \\
& \int_{0}^{\infty} \mathrm{B}\left(\mathrm{k}_{\mathrm{c}}\right) \mathrm{Y}\left(\mathrm{k}_{\mathrm{c}}\right)\left[1-\Gamma_{\mathrm{b}}\left(\mathrm{k}_{\mathrm{c}}\right)\right] \mathrm{J}_{1}\left(\mathrm{k}_{\mathrm{c}} \mathrm{r}\right) \mathrm{k}_{\mathrm{c}} \mathrm{dk}_{\mathrm{c}}=\frac{\mathrm{A}(1-\Gamma)}{\eta_{1} \mathrm{r}} \quad \mathrm{a} \leq \mathrm{r} \leq \mathrm{b}
\end{aligned}
$$


Multiply $\mathrm{J}_{1}\left(\mathrm{k}_{\mathrm{c}}^{\prime} \mathrm{r}\right) \mathrm{r}$ to two sides of equation (5), and then take an integral with the form $\int_{0}^{\infty} \mathrm{dr}$, we get,

$$
\int_{0}^{\infty} \int_{0}^{\infty} \mathrm{B}\left(\mathrm{k}_{\mathrm{c}}\right)\left[1+\Gamma_{\mathrm{b}}\left(\mathrm{k}_{\mathrm{c}}\right)\right] \mathrm{J}_{1}\left(\mathrm{k}_{\mathrm{c}} \mathrm{r}\right) \mathrm{k}_{\mathrm{c}} \mathrm{dk} \mathrm{k}_{\mathrm{c}} \cdot \mathrm{J}_{1}\left(\mathrm{k}_{\mathrm{c}}^{\prime} \mathrm{r}\right) \mathrm{rdr}=\int_{\mathrm{a}}^{\mathrm{b}} \frac{\mathrm{A}(1+\Gamma)}{\mathrm{r}} \cdot \mathrm{J}_{1}\left(\mathrm{k}_{\mathrm{c}}^{\prime} \mathrm{r}\right) \mathrm{rdr}
$$

The integral order of the left of equation (7) is rearranged as,

$$
\text { left }=\int_{0}^{\infty} \mathrm{B}\left(\mathrm{k}_{\mathrm{c}}\right)\left[1+\Gamma_{\mathrm{b}}\left(\mathrm{k}_{\mathrm{c}}\right)\right] \mathrm{k}_{\mathrm{c}}\left[\int_{0}^{\infty} \mathrm{J}_{1}\left(\mathrm{k}_{\mathrm{c}} \mathrm{r}\right) \mathrm{J}_{1}\left(\mathrm{k}_{\mathrm{c}}^{\prime} \mathrm{r}\right) \mathrm{rdr}\right] \mathrm{dk_{ \textrm {c } }}
$$

According to the orthogonality of Bessel functions, we get

$$
\int_{0}^{\infty} J_{n}\left(k_{c} r\right) J_{n}\left(k_{c}^{\prime} r\right) r d r=\frac{1}{k_{c}} \delta\left(k_{c}-k_{c}^{\prime}\right)
$$

According to the sifting properties of $\delta$ function:

$$
\int_{-\infty}^{\infty} \delta\left(t-t_{0}\right) f(t) d t=f\left(t_{0}\right)
$$

Then the equation (8) can be modified:

$$
\text { left }=\int_{0}^{\infty} \mathrm{B}\left(\mathrm{k}_{\mathrm{c}}\right)\left[1+\Gamma_{\mathrm{b}}\left(\mathrm{k}_{\mathrm{c}}\right)\right] \mathrm{k}_{\mathrm{c}} \frac{1}{\mathrm{k}_{\mathrm{c}}} \delta\left(\mathrm{k}_{\mathrm{c}}-\mathrm{k}_{\mathrm{c}}^{\prime}\right) \mathrm{dk}_{\mathrm{c}}=\mathrm{B}\left(\mathrm{k}_{\mathrm{c}}^{\prime}\right)\left[1+\Gamma_{\mathrm{b}}\left(\mathrm{k}_{\mathrm{c}}^{\prime}\right)\right]
$$

Since $\frac{d}{d x} J_{0}(x)=-J_{1}(x)$, the right of the equation (7) can be calculated:

$$
\text { right }=\int_{a}^{b} \frac{A(1+\Gamma)}{r} \cdot J_{1}\left(k_{c}^{\prime} r\right) r d r=A(1+\Gamma) \int_{a}^{b} J_{1}\left(k_{c}^{\prime} r\right) d r=A(1+\Gamma)\left[\frac{J_{0}\left(k_{c}^{\prime} a\right)-J_{0}\left(k_{c}^{\prime} b\right)}{k_{c}^{\prime}}\right]
$$

Then the equation (7) can be rearranged:

$$
\mathrm{B}\left(\mathrm{k}_{\mathrm{c}}^{\prime}\right)\left[1+\Gamma_{\mathrm{b}}\left(\mathrm{k}_{\mathrm{c}}^{\prime}\right)\right]=\mathrm{A}(1+\Gamma)\left[\frac{\mathrm{J}_{0}\left(\mathrm{k}_{\mathrm{c}}^{\prime} \mathrm{a}\right)-\mathrm{J}_{0}\left(\mathrm{k}_{\mathrm{c}}^{\prime} \mathrm{b}\right)}{\mathrm{k}_{\mathrm{c}}^{\prime}}\right]
$$

Let $\mathrm{k}_{\mathrm{c}}^{\prime}=\mathrm{k}_{\mathrm{c}}$, the equation (13) becomes,

$$
\mathrm{B}\left(\mathrm{k}_{\mathrm{c}}\right)=\frac{\mathrm{A}(1+\Gamma)}{1+\Gamma_{\mathrm{b}}\left(\mathrm{k}_{\mathrm{c}}\right)}\left[\frac{\mathrm{J}_{0}\left(\mathrm{k}_{\mathrm{c}} \mathrm{a}\right)-\mathrm{J}_{0}\left(\mathrm{k}_{\mathrm{c}} \mathrm{b}\right)}{\mathrm{k}_{\mathrm{c}}}\right]
$$

The equation (14) is substituted to equation (6) and takes an integral with $\int_{a}^{b} d r$ with the equation (6):

$$
\int_{\mathrm{a}}^{\mathrm{b}} \int_{0}^{\infty} \frac{\mathrm{A}(1+\Gamma)}{1+\Gamma_{\mathrm{b}}\left(\mathrm{k}_{\mathrm{c}}\right)}\left[\frac{\mathrm{J}_{0}\left(\mathrm{k}_{\mathrm{c}} \mathrm{a}\right)-\mathrm{J}_{0}\left(\mathrm{k}_{\mathrm{c}} \mathrm{b}\right)}{\mathrm{k}_{\mathrm{c}}}\right] \mathrm{Y}\left(\mathrm{k}_{\mathrm{c}}\right)\left[1-\Gamma_{\mathrm{b}}\left(\mathrm{k}_{\mathrm{c}}\right)\right] \mathrm{J}_{1}\left(\mathrm{k}_{\mathrm{c}} \mathrm{r}\right) \mathrm{dk_{ \textrm {c } }} \mathrm{dr}=\int_{\mathrm{a}}^{\mathrm{b}} \frac{\mathrm{A}(1-\Gamma)}{\eta_{1} \mathrm{r}} \mathrm{dr}
$$


Eliminating A and rearranging, (15) becomes,

$$
\int_{0}^{\infty}\left[\int_{\mathrm{a}}^{\mathrm{b}} \mathrm{J}_{1}\left(\mathrm{k}_{\mathrm{c}} \mathrm{r}\right) \mathrm{dr}\right] \mathrm{Y}\left(\mathrm{k}_{\mathrm{c}}\right) \frac{1-\Gamma_{\mathrm{b}}\left(\mathrm{k}_{\mathrm{c}}\right)}{1+\Gamma_{\mathrm{b}}\left(\mathrm{k}_{\mathrm{c}}\right)}\left[\frac{\mathrm{J}_{0}\left(\mathrm{k}_{\mathrm{c}} \mathrm{a}\right)-\mathrm{J}_{0}\left(\mathrm{k}_{\mathrm{c}} \mathrm{b}\right)}{\mathrm{k}_{\mathrm{c}}}\right] \mathrm{dk}_{\mathrm{c}}=\frac{(1-\Gamma)}{\eta_{1}(1+\Gamma)} \int_{\mathrm{a}}^{\mathrm{b}} \frac{1}{\mathrm{r}} \mathrm{dr}
$$

The result is:

$$
\frac{1-\Gamma}{1+\Gamma}=\frac{\eta_{1}}{\ln (\mathrm{b} / \mathrm{a})} \int_{0}^{\infty} \mathrm{Y}\left(\mathrm{k}_{\mathrm{c}}\right) \frac{1-\Gamma_{\mathrm{b}}\left(\mathrm{k}_{\mathrm{c}}\right)}{1+\Gamma_{\mathrm{b}}\left(\mathrm{k}_{\mathrm{c}}\right)} \cdot \frac{\left[\mathrm{J}_{0}\left(\mathrm{k}_{\mathrm{c}} \mathrm{a}\right)-\mathrm{J}_{0}\left(\mathrm{k}_{\mathrm{c}} \mathrm{b}\right)\right]^{2}}{\mathrm{k}_{\mathrm{c}}} \mathrm{dk}_{\mathrm{c}}
$$

$\mathrm{J}_{0}(\mathrm{x})$ is a Zero-order Bessel function of the first kind. It becomes the following:

$$
\frac{1-\Gamma}{1+\Gamma}=\frac{\eta_{1}}{\ln (\mathrm{b} / \mathrm{a})} \cdot \int_{0}^{\infty} \frac{\left[\mathrm{J}_{0}\left(\mathrm{k}_{\mathrm{c}} \mathrm{a}\right)-\mathrm{J}_{0}\left(\mathrm{k}_{\mathrm{c}} \mathrm{b}\right)\right]^{2}\left[1+2 \exp \left(-\sqrt{\mathrm{k}_{\mathrm{c}}^{2}-\omega^{2} \varepsilon_{0} \varepsilon_{\mathrm{s}} \mu_{0} \mu_{\mathrm{s}}} \times \mathrm{d}\right)\right] \varepsilon_{\mathrm{s}} i \omega \varepsilon_{0}}{\left[1-2 \exp \left(-\sqrt{\mathrm{k}_{\mathrm{c}}^{2}-\omega^{2} \varepsilon_{0} \varepsilon_{\mathrm{s}} \mu_{0} \mu_{\mathrm{s}}} \times d\right)\right] \mathrm{k}_{\mathrm{c}} \sqrt{\mathrm{k}_{\mathrm{c}}^{2}-\omega^{2} \varepsilon_{0} \varepsilon_{\mathrm{s}} \mu_{0} \mu_{\mathrm{s}}}} d \mathrm{k}_{\mathrm{c}}
$$

Because the other parameters are all known. The equation (18) is a nonlinear equation about independent variable $\varepsilon_{\mathrm{s}}$ and variable $\Gamma$. The question of solving permittivity becomes a process of solving this nonlinear equation.

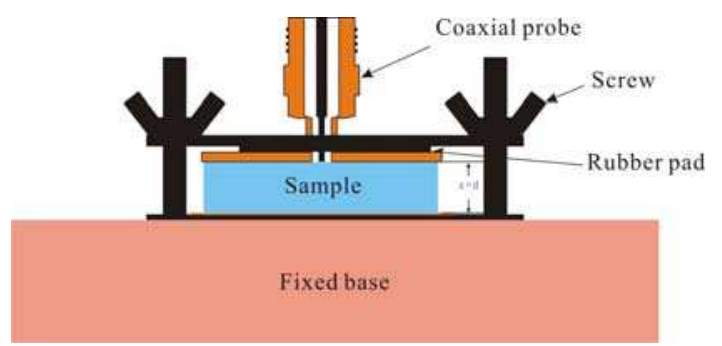

Fig. 3. Schematic diagram of rock sample holder

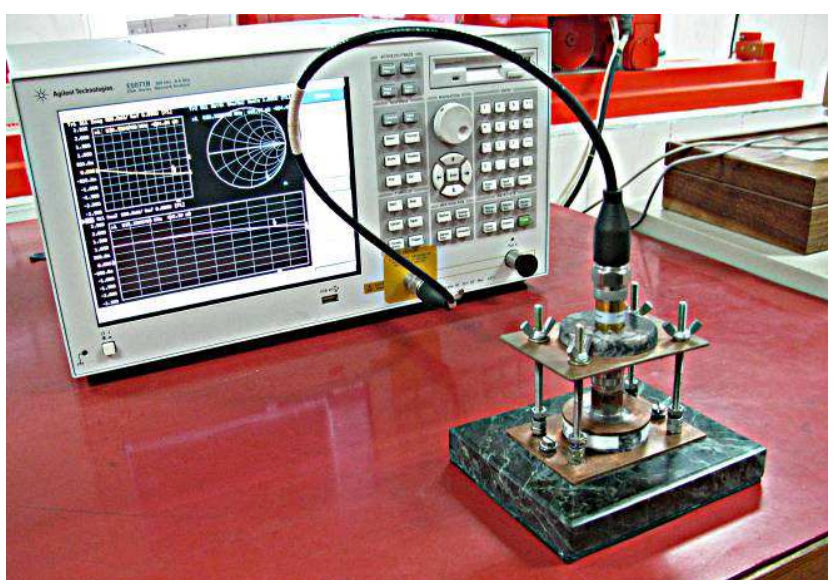

Fig. 4. VNA and the rock sample holder 
To avoid the influence of air-gap to the testing result, a rock sample holder is make as shown in fig. 3.

The practical testing equipment including a VNA is shown in Fig. 4.

In equation (17) and (18), because the Bessel function has oscillating property, the main difficulty focuses on the Bessel function with integral variable. Obviously these nonlinear equations have no analytical solution. So we uses numerical solution here. A big number (12500) is used for the positive infinite of the upper limit during the numerical intergal. The value of the big number is determined by different testing of many conditions.

\subsection{Calibration}

The calibration in this measurement includes two steps, one is the transmission line calibration, and the other is the probe calibration.

\subsubsection{Transmission line calibration}

The VNA is a exact device and is connected to coaxial probe through a coaxial cable. According to the operation requirement of the network analyzer, the coaxial line is calibrated using calibrating kits. The detailed operation process as follows.

1. VNA parameters setting. The frequency range is between $1 \mathrm{MHz}-1 \mathrm{GHz}$ in this test according to our request. Power can be selected by our need, for example, $0 \mathrm{dBm}$. Large power is believed to sense large sample volume. We choose 1000 sampling points here.

2. Calibration process. We use single port calibration here because we only measure S11. The calibration kits which including the device SHORT, LOAD, and OPEN are used to calibrate the VNA. After this process, the reference plane for VNA is at the end of the coaxial cable. However, because the reflection surface is on the flange surface, not the end of the cable, further calibration is still needed.

\subsubsection{Probe calibration}

Probe calibration is an indirect method. We use short-circuit, the air, and the de-ionized water to calibrate the probe.

If $\Gamma_{\mathrm{m}}$ is the reflection coefficient obtained through measuring and $\Gamma_{\mathrm{a}}$ is the practical reflection coefficient of probe terminal, $\Gamma_{\mathrm{m}}$ can be expressed as (Blackham \& Pollard, 1997):

$$
\Gamma_{\mathrm{m}}=\mathrm{e}_{\mathrm{d}}+\frac{\mathrm{e}_{\mathrm{r}} \Gamma_{\mathrm{a}}}{1-\mathrm{e}_{\mathrm{s}} \Gamma_{\mathrm{a}}}
$$

where, $e_{d}$ is the limited directivity error; $e_{r}$ is frequency response error; $e_{s}$ is equivalent source matching error. The reflection coefficient of the material $\Gamma_{\mathrm{a}}$ can be calculated through equation (17) or (18). Through measuring the reflection coefficient of three kinds of materials $\Gamma_{\mathrm{m}}$, the three equations about $\mathrm{e}_{\mathrm{d}}, \mathrm{e}_{\mathrm{r}}, \mathrm{e}_{\mathrm{s}}$ can be obtained. There are three variables and three equations, the error coefficients $e_{d}, e_{r}, e_{s}$ can be obtained.

Short-circuit, and air are ideal calibration materials. The third material must have known permittivity. The de-ionized water is selected as the third calibration material here. When it is of short-circuit, $\Gamma_{\mathrm{a}}=-1$; when the calibration material is air, the reflection coefficient of every frequency can be calculated through equation (17) or (18), because the permittivity of air is 1 . According to the same theory, the reflection coefficient of de-ionized water can be calculated. Here, the reflection coefficient of water is obtained through the Cole-Cole formula. 


$$
\varepsilon=\varepsilon^{\prime}-j \varepsilon^{\prime \prime}=\varepsilon_{\infty}+\frac{\varepsilon_{\mathrm{s}}-\varepsilon_{\infty}}{1+\left(j \omega / \omega_{0}\right)^{1-\alpha}}
$$

where, $\varepsilon_{\mathrm{s}}$ is a direct current permittivity. $\varepsilon_{\infty}$ is an optical frequency permittivity. $\omega_{0}$ is a Debye relaxation angle frequency. $\alpha$ is a Cole-Cole factor.

By substituting the reflection coefficient of air film $\Gamma_{\text {air_a }}$ and $\Gamma_{\text {air_m }}$, the reflection coefficient of de-ionized water $\Gamma_{\text {water } \_ \text {and }} \Gamma_{\text {water } m}$ and the reflection coefficient of short-circuit $\Gamma_{\text {short_a }}=-1$ and $\Gamma_{\text {short_m }}$ into the equation (19) separately. We get,

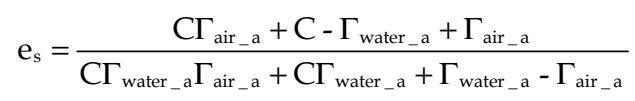

where, $\mathrm{C}=\frac{\Gamma_{\text {water }} \mathrm{m}-\mathrm{A}}{\mathrm{A}-\mathrm{B}}, \mathrm{A}=\Gamma_{\text {air__}_{-} \mathrm{m}}, \mathrm{B}=\Gamma_{\text {short_m }} \mathrm{m}$.

We can also get,

$$
\begin{gathered}
\mathrm{e}_{\mathrm{r}}=\frac{\Gamma_{\text {water_m }}-\mathrm{A}}{\frac{\Gamma_{\text {water_a }}}{1-\mathrm{e}_{\mathrm{s}} \Gamma_{\text {water_a }}}-\frac{\Gamma_{\text {air_a }}}{1-\mathrm{e}_{\mathrm{s}} \Gamma_{\text {air_a }}}} \\
\mathrm{e}_{\mathrm{d}}=\mathrm{A}-\frac{\mathrm{e}_{\mathrm{r}} \Gamma_{\text {air_a }}}{1-\mathrm{e}_{\mathrm{s}} \Gamma_{\text {air_a }}}
\end{gathered}
$$

It can be concluded based on the equation (19) that:

$$
\Gamma_{\mathrm{a}}=\frac{\Gamma_{\mathrm{m}}-\mathrm{e}_{\mathrm{d}}}{\mathrm{e}_{\mathrm{s}}\left(\Gamma_{\mathrm{m}}-\mathrm{e}_{\mathrm{d}}\right)+\mathrm{e}_{\mathrm{r}}}
$$

Equation (24) determines the second step calibration. Fig. 7 shows the comparison among results before and after calibration for PTFE and de-ionized water, separately.

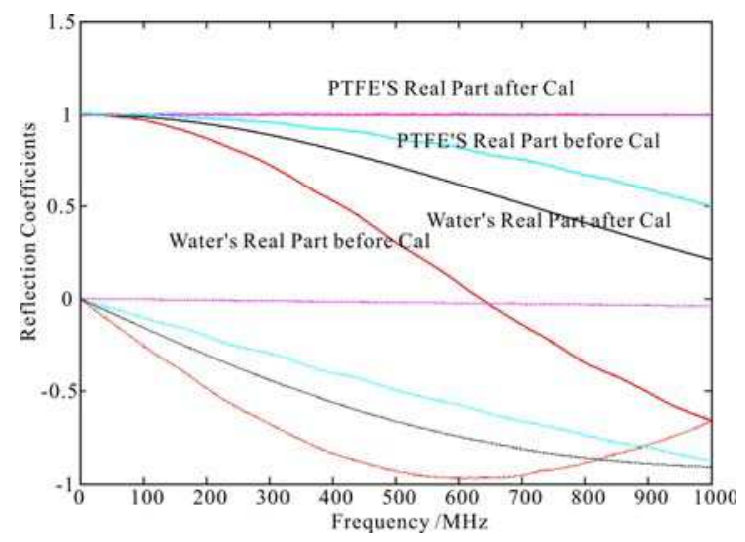

Fig. 5. Reflection coefficient before and after calibration

It can be seen that the real part of PTFE measured can be calibrated to around but different from 1 . 


\subsection{Inversion calculation and error evaluation}

If the permittivity of a material measured is known, the interface reflection coefficient (or admittance) can be calculated. This process is a forward one. The reverse process can be solved numerically. The following equation can be obtained from equation (18),

$$
\mathrm{Y}=\frac{1-\Gamma}{1+\Gamma}=\frac{\eta_{1}}{\ln (\mathrm{b} / \mathrm{a})} \int_{0}^{\infty} \mathrm{Y}\left(\mathrm{k}_{\mathrm{c}}\right) \frac{1-\Gamma_{\mathrm{b}}\left(\mathrm{k}_{\mathrm{c}}\right)}{1+\Gamma_{\mathrm{b}}\left(\mathrm{k}_{\mathrm{c}}\right)} \cdot \frac{\left[\mathrm{J}_{0}\left(\mathrm{k}_{\mathrm{c}} \mathrm{a}\right)-\mathrm{J}_{0}\left(\mathrm{k}_{\mathrm{c}} \mathrm{b}\right)\right]^{2}}{\mathrm{k}_{\mathrm{c}}} \mathrm{dk}_{\mathrm{c}}
$$

The solution is:

$$
\Gamma=\frac{1-\mathrm{Y}}{1+\mathrm{Y}}
$$

Because it is a complex calculation, the objective function is defined as

$$
\mathrm{f}(\varepsilon)=\mathrm{a}\left|\operatorname{Re}\left(\Gamma_{\mathrm{m}}-\Gamma_{\mathrm{c}}\right)\right|^{2}+\left|\operatorname{Im}\left(\Gamma_{\mathrm{m}}-\Gamma_{\mathrm{c}}\right)\right|^{2}
$$

$\alpha$ is a weighting coefficient in this equation, $\Gamma_{\mathrm{m}}$ and $\Gamma_{\mathrm{c}}$ are measured and the calculated reflection coefficients. The real part and the imaginary part should be treated equally to avoid that the large part dominates over the small part too much. This is the typical optimization problem. Here, $\varepsilon$ can be thought as a complex-single variable. But the most mathematical software optimization tool can not process complex variable optimization question. So the complex permittivity is divided to real part and imaginary part. The variable $x$ is a vector array, where, $x_{1}=\operatorname{Re}(\varepsilon), x_{2}=\operatorname{Im}(\varepsilon)$. The selection of weighting coefficient is based on the numerous tests.

We solve the optimization process using the simplex method. The value of $f(\varepsilon)$ after the optimization for every frequency is displayed in Fig. 6 for the material PTFE. It can be seen that the precision is very well. When the optimization stops, the objective function of minimum point satisfy the error requirement.

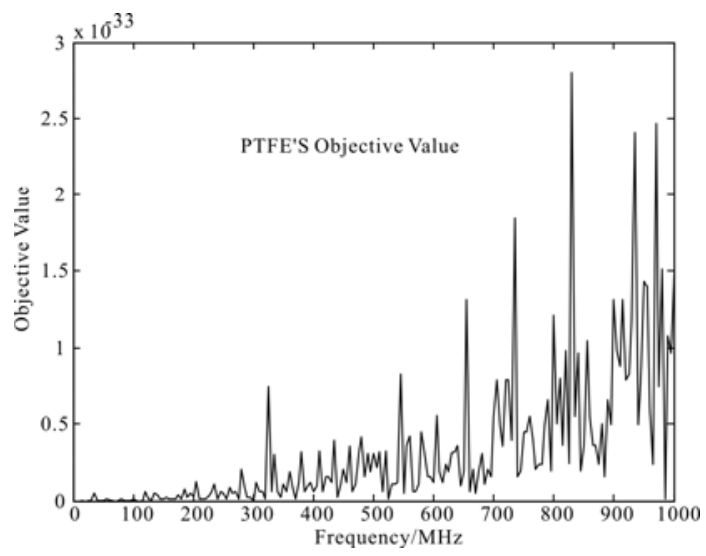

Fig. 6. The value of optimization objective function

We testify this technique using a standard material PTFE, air, and methanol. 
We first test this technique with PTFE whose thickness is $10.50 \mathrm{~mm}$ in this paper and has permittivity of 2.1-j0.0004 (Li \& Chen, 1995) in microwave band. Because the imaginary part can not be measured exactly for lowly lossy medium (Wu et al., 2001) by this technique, we ignore the analysis for the imaginary part. The inverted permittivity is displayed in Fig. 7. The real part relative error at every frequency is displayed in Fg. 8.
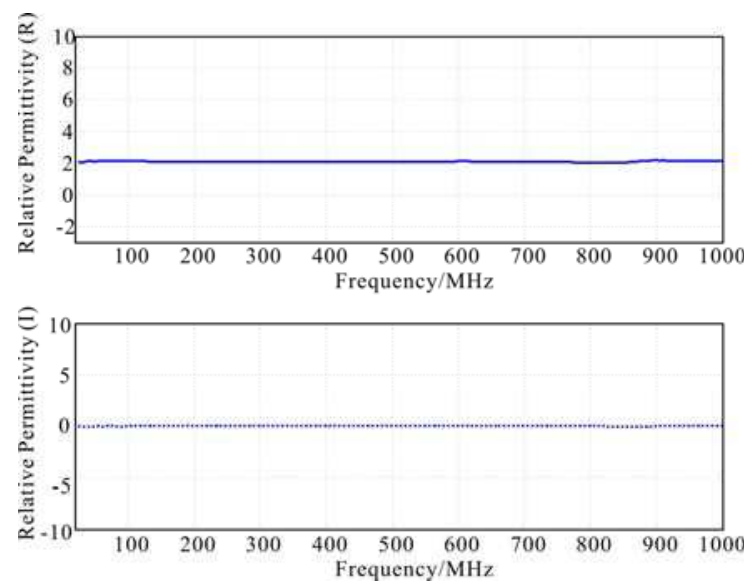

Fig. 7. Permittivity of PTFE sample

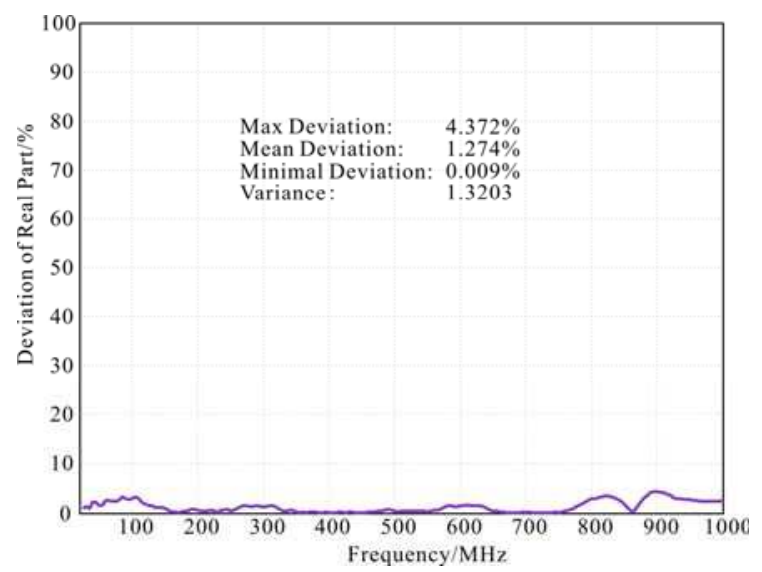

Fig. 8. Real part relative error of the permittivity of PTFE sample

We noticed that the arisen relative error is within $5 \%$ basically. The average relative error is $1.2749 \%$. One of the many reasons leading to the error is the air gap between the flange and the sample. The main reasons of producing air gap are that the upper surface and down surface are not parallel and clean enough, and the upper surface and the down surface do not touch enough with coaxial probe flange-plane and short-circuit board, although we already tried our best.

The permittivity calculated by the air film is displayed in Fig. 9. 


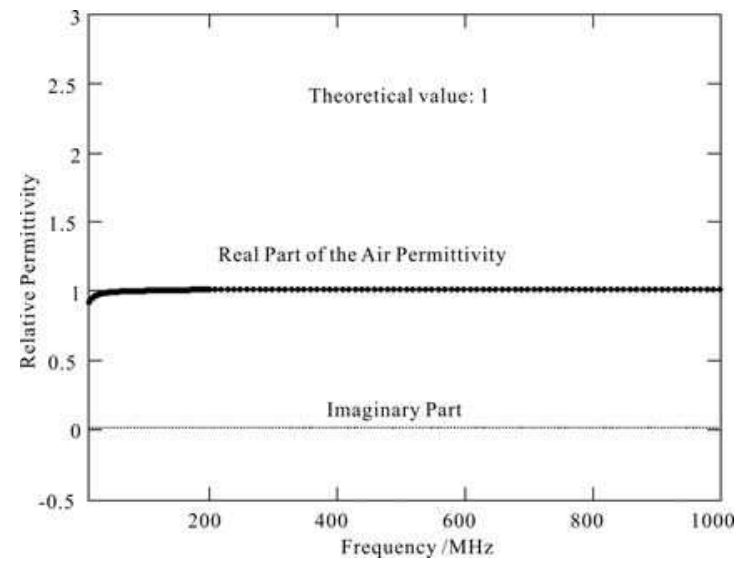

Fig. 9. Permittivity of the air

The relative error is $0.7692 \%$. Because the air is a kind of calibration material, the permittivity of air calculated should be theoretical value 1 .The relative error is below $0.8 \%$. It proves the validity of inversion process.

The measured permittivity for methanol is displayed in Fig. 10.

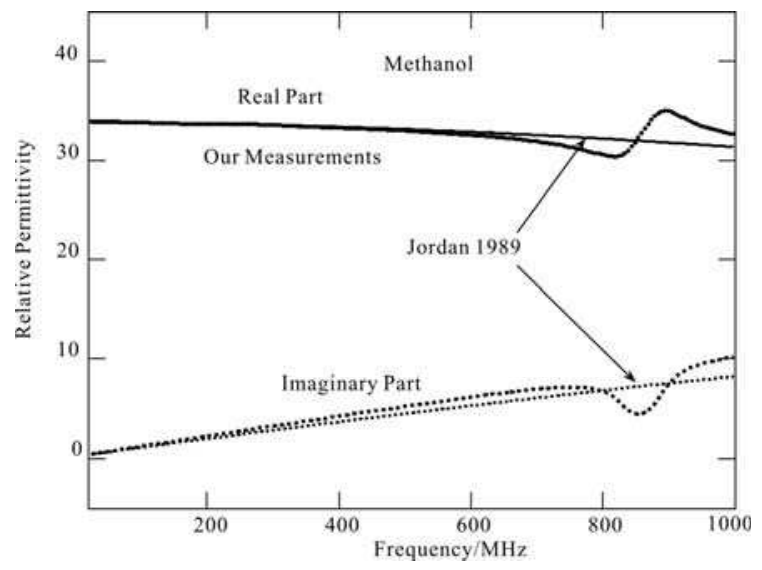

Fig. 10. Permittivity of methanol

The measured permittivity for methanol is compared with the theoritical values which is calculated by the debye equation or cole-cole equation (Jordan et al., 1978) as shown in Fig. 10. The measured data is accetable except that they have clear difference with the theotitical ones at high frequency range. The reducement of this error could be the future topic.

\section{Measured results and analysis}

342 rocks and ores sample within 31 categories from 6 mines are measured and analyzed in this part by using open-coaxial probe technique. The photos for these rocks and ores samples are shown in Fig. 11. 

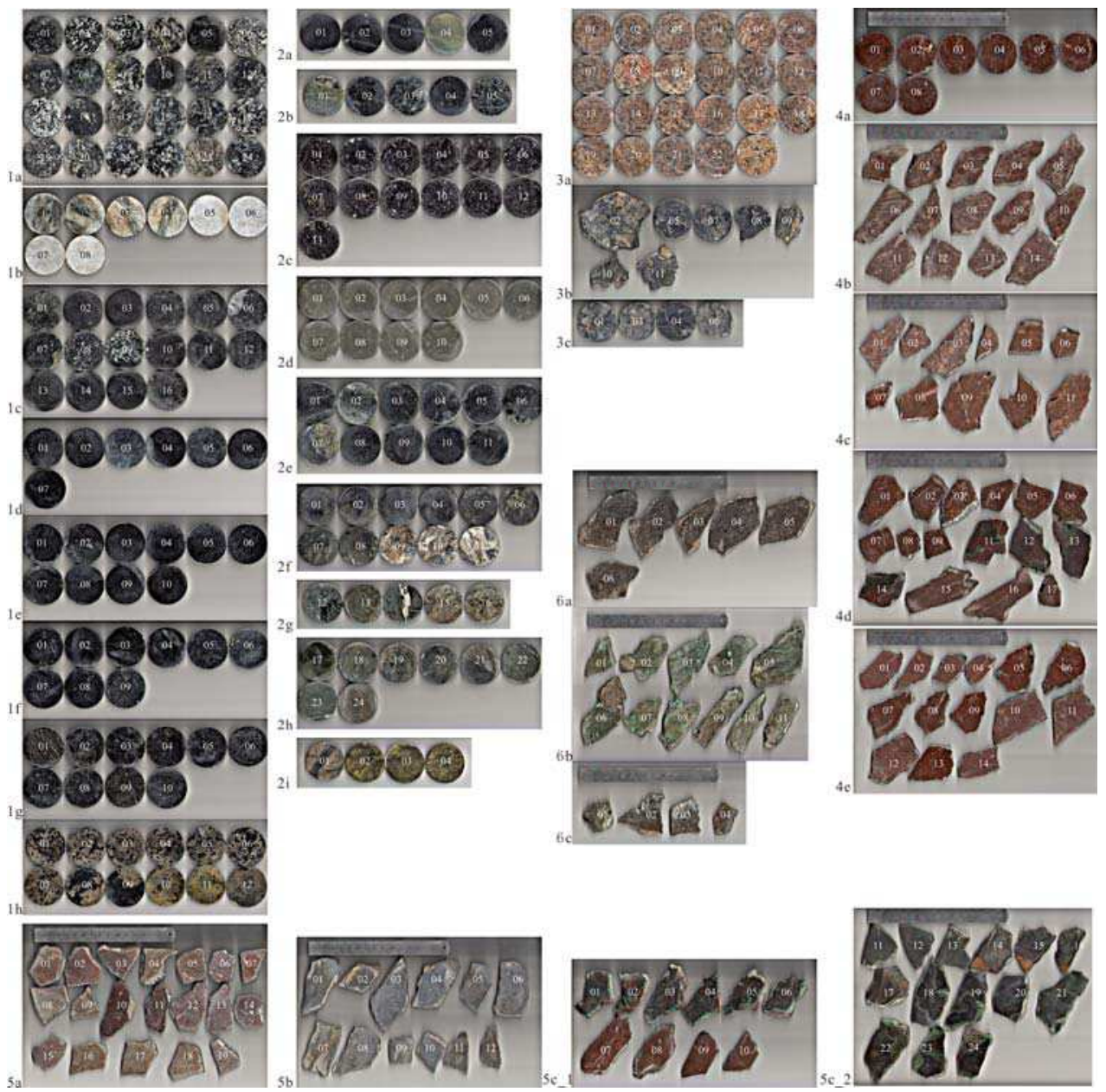

Fig. 11. Photographs of the rocks and ores samples from 6 metal mines

\subsection{Samples from the Changren nickel-copper mine, Jilin, China}

Table 1 shows the messages of rocks and ores from the Changren nickel-copper mine, Jilin, China.

Fig.12 shows marbles permittivities as an example, the solid and the dashed lines denote the real parts and the imagery parts. We find the values are diverse for the same rock. We think this kind of diversity is due to the fact of that the probe senses a small range and the samples are in-homogeneous. Therefore, we use the averaging value of these data to represent this sample, because the averaging could reflect the total characteristic.

Fig. 13 shows the average permittivities of all rocks and ores from the Changren nickelcooper mine, China. We find high grade ore and medium grade ore have highest values, then the values range from high to low are the pyroxene peridotite, low grade ore, light alterative bornblende pyroxenite, marble, hybrid diorite, granitization granite. 


\begin{tabular}{|c|c|c|c|c|}
\hline Rocks & Rock or Ore names & Fig. no. & Measured permittivity & Sample number \\
\hline 1 & granite & $11(1 \mathrm{a})$ & $5-7.5$ & 25 \\
\hline 2 & marble & $11(1 \mathrm{~b})$ & $5-10$ & 8 \\
\hline 3 & hybrid diorite & $11(1 \mathrm{c})$ & $5-10$ & 16 \\
\hline 4 & altered hornblende pyroxenite & $11(1 \mathrm{~d})$ & $5-17$ & 7 \\
\hline 5 & pyroxene peridotite & $11(1 \mathrm{f})$ & $10-20$ & 10 \\
\hline ores: & & & & 9 \\
\hline 6 & low-grade ore & $11(1 \mathrm{~g})$ & $9-23$ & 10 \\
\hline 7 & medium-grade ore & $11(1 \mathrm{f})$ & $20-70$ & 12 \\
\hline 8 & high-grade ore & $11(1 \mathrm{~h})$ & $5-95$ & \\
\hline
\end{tabular}

Table 1. Rocks and ores from the Changren nickel-copper mine, Jilin, China
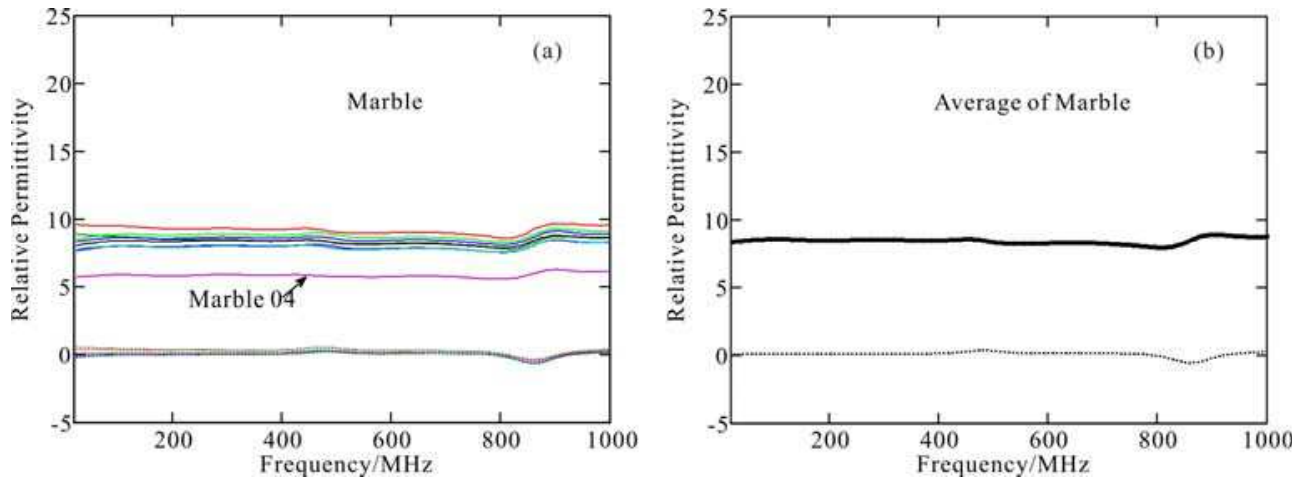

Fig. 12. Permittivity of marbles. (a) 8 Marble's samples permittivities; (a) average of mable samples' permittivities

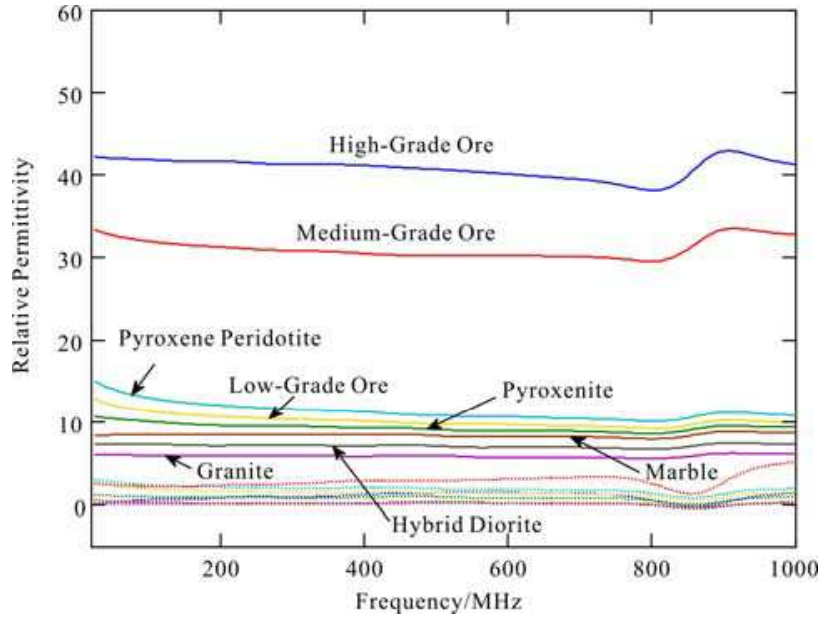

Fig. 13. Averaged relative permittivities of rocks and ores from the Changren nickel-cooper mine 
Actually, the pyroxene peridotite, light alterative bornblende pyroxenite are basic rocks and ultra-basic rock which were ore carrier. When ore's grade is low, the permittivity represents the carrier rock's property. These basic rocks and ultra-basic rock come from tectonic emplacement. The granitized granite is the host rock which has distinguished lower values. These measured data show optimistic aspect for borehole radar detection for metal ore-body.

\subsection{The samples from the Huanghuagou lead-zinc mine, Chifeng, Inner Mongolian, China}

The table 2 shows the message of rocks and ores from the Huanghuagou Lead-Zinc mine Chifeng, China. Ores and rocks ranked by permittivity from high to low are high-grade ore, pyrite, medium-grade ore, dacitoid crystal tuff, low-grade ore, crystal tuff, tuffaceous breccia, tuffaceous sandstone, and dacite. The high-grade ore, pyrite, and the medium-grade ore are distinguishable from each other and the others.

\begin{tabular}{|c|c|c|c|c|}
\hline Rocks & Rock or Ore names & Fig. no & permittivity & Samples number \\
\hline 1 & tuffaceous fine-grained sandstone & $11(2 \mathrm{a})$ & $5-7$ & 5 \\
\hline 2 & tuffaceous breccia & $11(2 \mathrm{~b})$ & $5-6$ & 5 \\
\hline 3 & dacitoid crystal tuff & $11(2 \mathrm{c})$ & $5.5-8$ & 13 \\
\hline 4 & dacite & $11(2 \mathrm{~d})$ & $5.5-6$ & 10 \\
\hline 5 & crystal tuff & $11(2 \mathrm{e})$ & $5-7.5$ & 11 \\
\hline Ores & & & \\
\hline 6 & high-grade ore & $11(2 \mathrm{f})$ & $10-70$ & 11 \\
\hline 7 & medium-grade ore & $11(2 \mathrm{~g})$ & $10-12$ & 5 \\
\hline 8 & low-grade ore & $11(2 \mathrm{~h})$ & $5-10$ & 8 \\
\hline 9 & pyrite & $11(2 \mathrm{i})$ & $20-40$ & 4 \\
\hline
\end{tabular}

Table 2. Messages of the Huanghuagou lead-zinc mine, Chifeng, Inner Mongolian, China

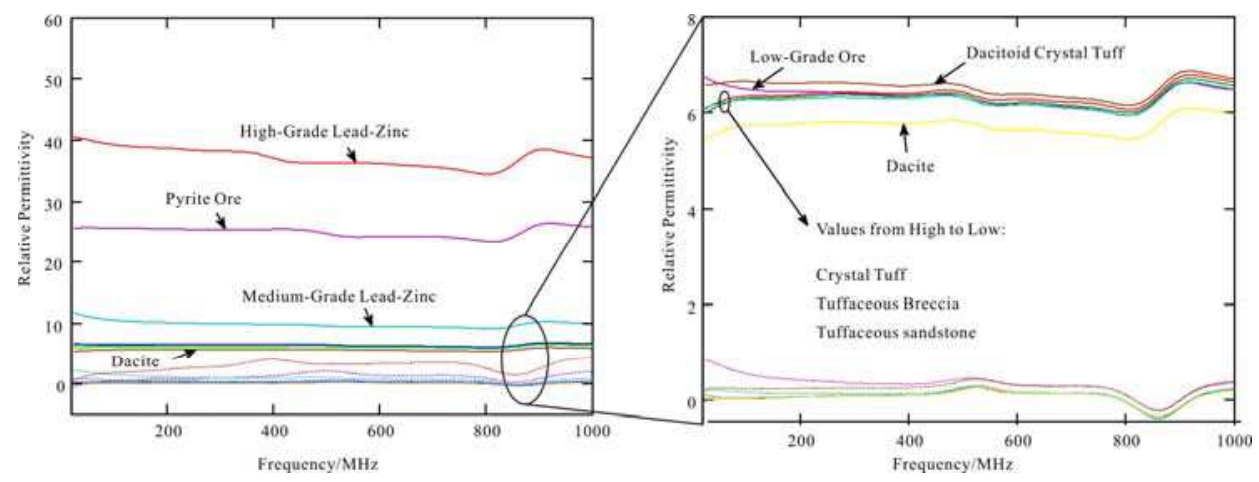

Fig. 14. Averaging permittivities of ores and rocks from the Huanghuagou lead-zinc mine, Chifeng, Inner Mongolian, China

\subsection{Samples from the Nianzigou molybdenum mine, Chifeng, Inner Mongolian, China} The table 3 shows the messages of rocks and ores from the Nianzigou molybdenum mine, Chifeng, Inner Mongolian, China. Ores and rocks ranked by permittivity from high to low are high-grade ore, low-grade ore, and altered K-feldspar granite. The high-gride ore is 
distinguishable from other two, and the low-grade ore shows the nearly same permittivity as altered K-feldspar grinate.

\begin{tabular}{|c|c|c|c|c|}
\hline Rocks & Rock or Ore names & Fig. no & permittivity & Samples number \\
\hline 1 & altered K-feldspar granite & $11(3 \mathrm{a})$ & $4.5-7.5$ & 23 samples \\
\hline Ores & & & & \\
\hline 2 & high-grade ore & $11(3 \mathrm{~b})$ & $5-15$ & 7 (No: 02, 05, 07, 08, 09, 10, 11) \\
\hline 3 & low-grade ore & $11(3 \mathrm{c})$ & $4-10$ & 4 (No: 01, 03, 04, 06) \\
\hline
\end{tabular}

Table 3. Messages of rocks and ores from the Nianzigou molybdenum mine, Chifeng, Inner Mongolian, China

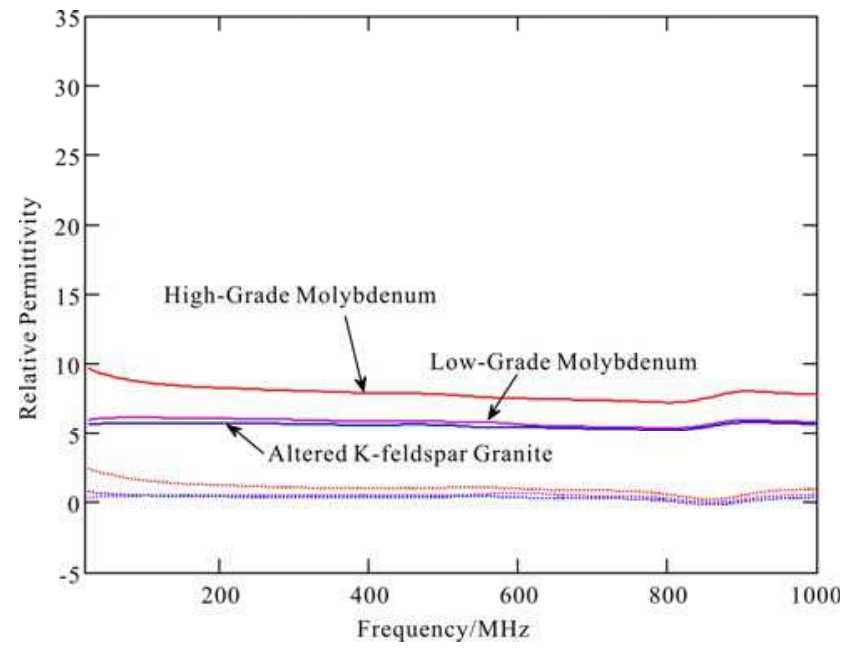

Fig. 15. Averaging permittivities of the rocks and ores from the Nianzigou molybdenum mine, Chifeng, Inner Mongolian, China

\subsection{Samples from the Qunji copper mine, Xinjiang, China}

The table 4 shows the messages of rocks and ores from the Qunji Copper mine, Xinjiang, China. Ores and rocks ranked by permittivity from high to low are albitophyre ore, quartz albitophyre, breccia porphyry, malachite copper oxide ore, and albite rhyolite porphyry. The albitophyre ore is clearly distinguishable from the others in the real part. Other rocks and ore are ambitious in permittivity.

\begin{tabular}{|c|c|c|c|c|}
\hline Rocks & Rock or Ore names & Fig. no & Permittivity & Samples number \\
\hline 1 & albite rhyolite porphyry (core) & $11(4 \mathrm{a})$ & $5-5.5$ & 8 \\
\hline 2 & breccia porphyry & $11(4 \mathrm{~b})$ & $5-5.5$ & 14 \\
\hline 3 & quartz albitophyre & $11(4 \mathrm{c})$ & $5-7.5$ & 11 \\
\hline Ores & & & & \\
\hline 4 & albitophyre ore & $11(4 \mathrm{~d})$ & $5-10$ & $16($ No $: 01-09,11-17)$ \\
\hline 5 & malachite oxide ore & $11(4 \mathrm{e})$ & $5-5.5$ & $14($ No. $: 01-14)$ \\
\hline
\end{tabular}

Table 4. Messages of rocks and ores from the Qunji Copper mine, Xinjiang, China 


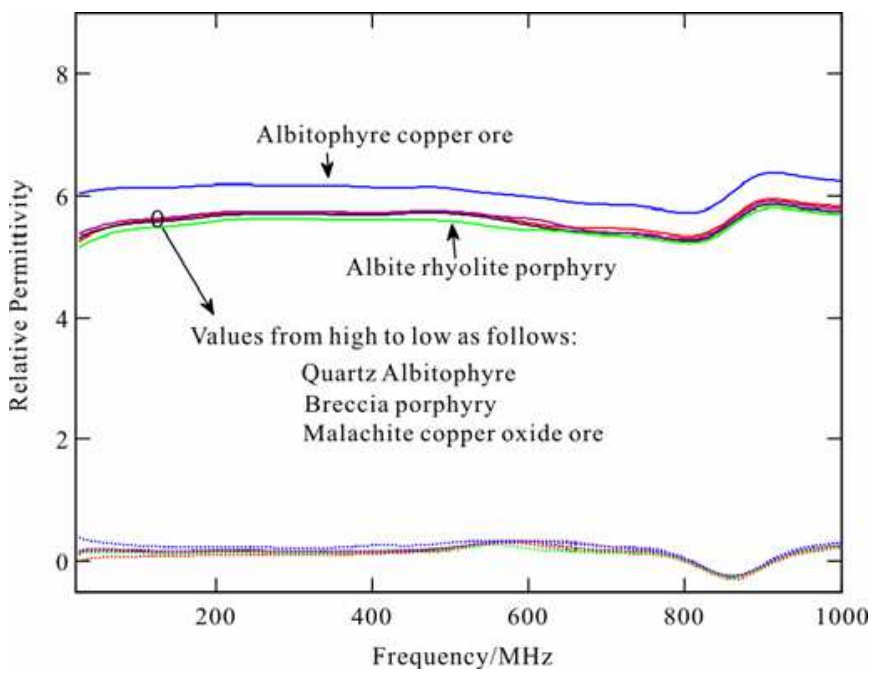

Fig. 16. Average permittivities of rocks and ores from the Qunji Copper mine, Xinjiang, China

\subsection{Samples from the Musi copper mine, Xinjiang, China}

The table 5 shows the messages of rocks and ores from the Musi copper mine, Xinjiang, China. Ores and rocks ranked by permittivity from high to low are vesicular amygdaloidal andesite, massive diorite, and andesitic copper ore. The andesitic copper ore is distinguishable from the others and shows low permittivity characteristic which is opposite to other mines.

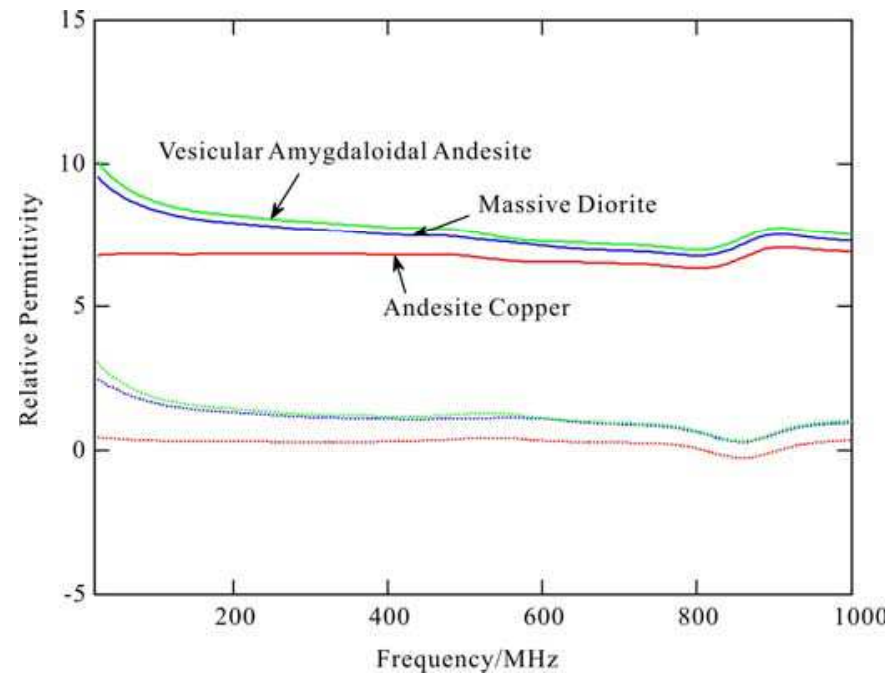

Fig. 17. Averaging permittivities of rocks and ores from the Musi copper mine, Xinjiang, China 


\begin{tabular}{|c|c|c|c|c|}
\hline Rocks & Rock or Ore names & Fig. no & Permittivity & Samples number \\
\hline 1 & vesicular amygdaloidal andesite & $11(5 \mathrm{a})$ & $5.5-12.5$ & 19 samples \\
\hline 2 & massive diorite & $11(5 \mathrm{~b})$ & $7.5-11$ & 12 samples \\
\hline Ores & & & & Total:24 \\
\hline 3 & andesitic copper ore & $11\left(5 \mathrm{c} \_1 ; 5 c \_2\right)$ & $5-10$ & 24 samples \\
\hline
\end{tabular}

Table 5. Messages of rocks and ores from the Musi copper mine, Xinjiang, China

\subsection{Samples from the Zengnan copper mine, Xinjiang, China}

The table 6 shows the messages of rocks and ores from the Zengnan copper mine, Xinjiang, China. Ores and rocks ranked by permittivity from high to low are lead-zinc ore, copper ore, and glutenite. Three of them can be distinguished from each other.

\begin{tabular}{|c|c|c|c|c|}
\hline Rocks & Rock or Ore names & Fig. no & Permittivity & Samples number \\
\hline 1 & glutenite & $11(6 \mathrm{a})$ & $8-14$ & 6 \\
\hline Ores & & & & 11 \\
\hline 2 & copper ore & $11(6 \mathrm{~b})$ & $8-40$ & 4 \\
\hline 3 & lead-zinc ore & $11(6 \mathrm{c})$ & $15-45$ & \\
\hline
\end{tabular}

Table 6. Messages of rocks and ores from the Zengnan copper mine, Xinjiang, China

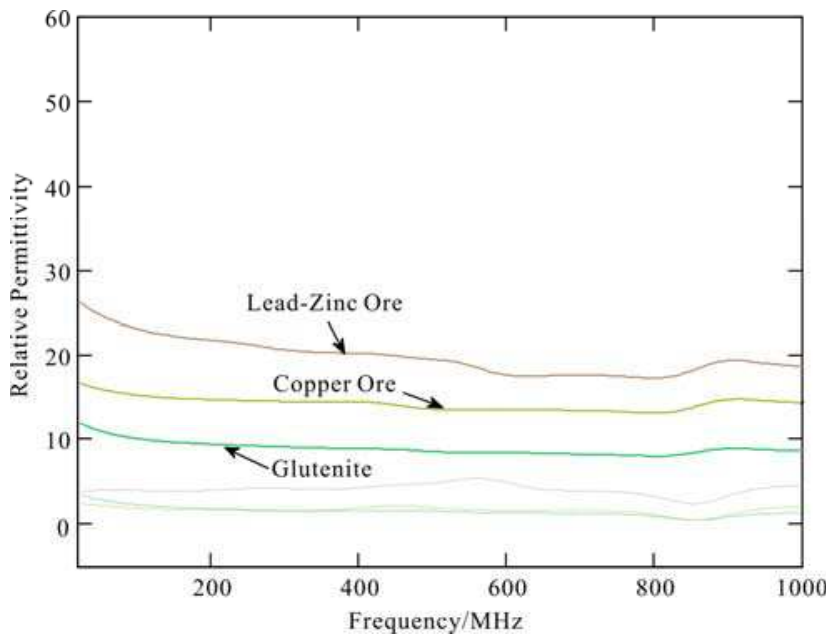

Fig. 18. Averaging permittivities of rocks and ores from the Zengnan copper mine, Xinjiang, China

\section{Conclusion}

Open-ended coaxial technique can measure the permittivity in wide frequency range quickly. The sample machining is relatively simple, and only the smooth surfaces of the sample sheets are required. Because the sensing range of the probe concentrates mainly at the center of the probe and the samples measured are no so homogeneous, we use averaging value from several samples of a rock or ore to reduce the random effect due to their in- 
homogeneity. It is shown that permittivity of metal ore is higher than other rocks, and highgrade ore is distinguishable from surrounding rocks. These measurements provide insights into the wide-frequency permittivity of metal ores and rocks, and also provide basis for electromagnetic exploration by borehole radar.

There are still couple of problems with the current research. The sizes of the flange, the aperture of the probe, sheet sample thickness, are not optimized yet. The sensing area for the current probe is small for the inhomogeneous rocks and ores. These are all future works for us.

\section{Acknowledgment}

This research is supported by the National Natural Science Foundation of China (Grant No 40874073 and 41074076), and by the National High-Tech R\&D Program 863 (Grant No 2008AA06Z103)

\section{References}

Blackham, D.V. \& Pollard, R. D. (1952). An improved technique for permittivity measurements using a coaxial probe. IEEE Transactions on Instrumentation and Measurement, Vol. 46, No. 5, (Sept., 1997), pp.1093-1099, ISSN 0018-9456

Coutanceau-Monteil, N., \& Jacquin, C. (1960). Improvements of the coaxial line technique for measuring complex dielectric permittivity of centimetric samples in the 20 to $1000 \mathrm{MHz}$ range: application to sedimentary rocks. Log Analyst, Vol. 34, No. 5, (September-October, 1993), PP. 21-33, ISSN 1529-9074

Daniels, D. (2004). Ground Penetrating Radar, 2nd Edition, The Institution of Engineering and Technology, ISBN 0863413609, London, United Kingdom.

Fan S.; Staebellk K. \& Misra D. (1952). Static analysis of an open-ended coaxial line terminated by layered media. IEEE Transactions on Instrumentation and Measurement, Vol. 39, No. 2, (March, 1990), pp.435-437, ISSN 0018-9456

Hoshina, S.; Kanai, Y. \& Miyakawa, M. (1965). A numerical study on the measurement region of a coaxial probe used for complex permittivity measurement. IEEE Trans. Magn, Vol. 37, No. 5, (Sept., 2001), pp. 3311-3314, ISSN 0018-9464

Jol, H. M. (2009). Ground Penetrating Radar Theory and Applications, ELSEVIER, ISBN 0444533486, Amsterdam, the Netherlands.

Jordan, B P ; Sheppard, R J \& Szarnowski, S. (1950). The dielectric properties of formamide, ethanediol and methanol. J. Phys. D: Appl. Phys, Vol. 11, No. 5, (April, 1978), pp. 695-701, ISSN 0022-3727

Kraszewski, A.W. (1965). Microwave aquametry - A review. Journal of Microwave Power, Vol. 15, No. 4, (1980), pp. 209-220, ISSN 0022-2739

Li, C. L. \& Chen, K. M. (1952). Determination of electromagnetic properties of materials using flanged open-ended coaxial probe-full-wave analysis. IEEE Transactions on Instrumentation and Measurement, Vol. 44, No.1, (Jan., 1995), pp. 19-27, ISSN 00189456

Misra, D. K. (1963). A quasi-static analysis of open-ended coaxial lines. IEEE Transactions on Microwave Theory and Techniques, Vol. 35, No. 10, (1987), pp. 925-928, ISSN 00189480 
Nelson, S.O \& Bartley, P. G. (1952). Open-ended coaxial line permittivity measurements on pulverized materials. IEEE Transactions on Instrumentation and Measurement, Vol. 47, No.1, (Jan., 1998), pp. 133-137, ISSN 0018-9456

Nicolson, A. M. \& Ross, G. (1952). Measurement of intrinsic properties of Materials by time domain techniques. IEEE Trans on Instrument $\mathcal{E}$ Measurement, Vol. IM-19, No. 4, (November 1970), pp. 377-382, ISSN 0018-9456

Nyshadham, A.; Sibbaldcl, C. L. \& Stuchly, S. S. (1963). Permittivity measurements using open-ended sensors and reference liquid calibration--an uncertainty analysis. IEEE Transactions on Microwave Theory and Techniques, Vol. 40, No. 2, (Feb., 1992), pp. 305314, ISSN 0018-9480

Roberts, S. R. \& Hippel, A. Von. (1930). A new method for measuring dielectric constant and loss in the range of centimeter wave. Journal of Applied Physics, Vol. 17, No. 7, (July, 1946), pp. 610-616, ISSN 0021-8979

Shen, L. C. (1961). A laboratory technique for measuring dielectric properties of core samples at ultrahigh frequencies. Society of Petroleum Engineers Journal, Vol. 25 No. 4, (April, 1985), pp. 502-514, ISSN 0197-7520

Shi, X. D. \& Shen, L. C. (1958). Dielectric properties of reservoir rocks at very-high frequencies. ACTA GEOPHYSICA SINICA, Vol. 32, No. 1, (Jan. 1989) pp. 99-110, ISSN 00015733

Shen, L.C.; Marouni, H.; Zhang, Y.X. \& Shi, X.D. (1963). Analysis of the parallel disk sample holder for dielectric permittivity measurement, IEEE transaction on geoscience and remote sensing, Vol. GE-25, No.5, (Sept. 1987), pp. 534-540, ISSN 0196-2892

Stuchly, M. A. \& Stuchly S. S. (1952). Coaxial line reflection methods for measuring dielectric properties of biological substances at radio and microwave frequencie-a review. IEEE Trans. Instrum. Meas., Vol. 29, No.3, (Sept., 1980), pp.176-183, ISSN 0018-9456

Venkatesh, M. S. \& Raghavan, G. S. V. (1949). An overview of dielectric properties measuring techniques. CANADIAN BIOSYSTEMS ENGINEERING, Vol. 47, No. 7, (2005), pp. 15-30, ISSN1492-9058

Weir, W. B.(1913). Automatic Measurement of Complex Dielectric Constant and Permeability at Microwave Frequency. Proc. IEEE, Vol. 62, No. 1, (Jan. 1974), pp.3336, ISSN 0018-9219

Wei, W. \& Sridhar, W. (1963). Radiation-corrected open-ended coax line technique for dielectric measurements of liquids up to $20 \mathrm{GHz}$. IEEE Transactions on Microwave Theory and Techniques, Vol. 39, No.3, (March, 1991), pp. 526-531, ISSN 0018-9480

Wu, M. Z.; Yao, X. \& Zhang, L, Y. (2000). An improved coaxial probe technique for measuring microwave permittivity of thin dielectric materials. Measurement Science and Technology, Vol. 11, No. 11, (2000), pp. 1617-1622, ISSN 0957-0233

Zheng, H. \& Smith, C. E. (1991). Permittivity measurement using a short open-ended coaxial line probe. IEEE Microw. Guided Wave Lett, Vol. 1, No.11, (November, 1991), pp. 337339, ISSN 1051-8207 


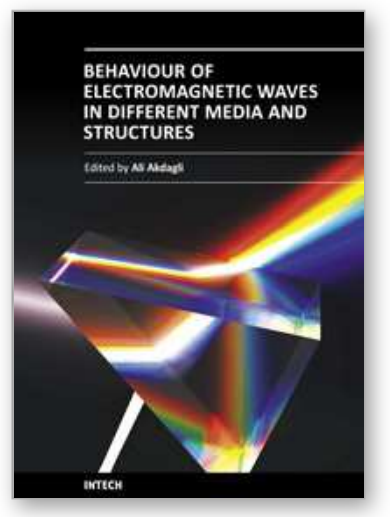

\author{
Behaviour of Electromagnetic Waves in Different Media and \\ Structures \\ Edited by Prof. Ali Akdagli
}

ISBN 978-953-307-302-6

Hard cover, 440 pages

Publisher InTech

Published online 09, June, 2011

Published in print edition June, 2011

This comprehensive volume thoroughly covers wave propagation behaviors and computational techniques for electromagnetic waves in different complex media. The chapter authors describe powerful and sophisticated analytic and numerical methods to solve their specific electromagnetic problems for complex media and geometries as well. This book will be of interest to electromagnetics and microwave engineers, physicists and scientists.

\title{
How to reference
}

In order to correctly reference this scholarly work, feel free to copy and paste the following:

Sixin Liu, Junjun Wu, Lili Zhang and Hang Dong (2011). Wide-band Rock and Ore Samples Complex Permittivity Measurement, Behaviour of Electromagnetic Waves in Different Media and Structures, Prof. Ali Akdagli (Ed.), ISBN: 978-953-307-302-6, InTech, Available from: http://www.intechopen.com/books/behaviorof-electromagnetic-waves-in-different-media-and-structures/wide-band-rock-and-ore-samples-complexpermittivity-measurement

\section{INTECH}

open science | open minds

\section{InTech Europe}

University Campus STeP Ri

Slavka Krautzeka 83/A

51000 Rijeka, Croatia

Phone: +385 (51) 770447

Fax: +385 (51) 686166

www.intechopen.com

\section{InTech China}

Unit 405, Office Block, Hotel Equatorial Shanghai

No.65, Yan An Road (West), Shanghai, 200040, China

中国上海市延安西路65号上海国际贵都大饭店办公楼 405 单元

Phone: +86-21-62489820

Fax: +86-21-62489821 
(C) 2011 The Author(s). Licensee IntechOpen. This chapter is distributed under the terms of the Creative Commons Attribution-NonCommercialShareAlike-3.0 License, which permits use, distribution and reproduction for non-commercial purposes, provided the original is properly cited and derivative works building on this content are distributed under the same license. 